\title{
Temperature-Dependent Growth of Crystalline Silicon Quantum Dots Embedded in Silicon Nitride
}

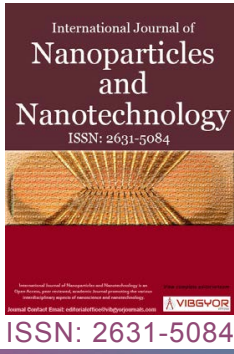

\section{Baek Hyun Kim ${ }^{1 *}$ and Seong-Ju Park ${ }^{2}$}

${ }^{1}$ Department of Electrical and Computer Engineering, University of Missouri, Columbia, USA

${ }^{2}$ Department of Materials Science and Engineering, Nanophotonic Semiconductors Laboratory, Gwangju Institute of Science and Technology, Gwangju, Republic of Korea

\begin{abstract}
The crystalline silicon quantum dots (Si QDs) depending on growth temperature were investigated using plasma enhanced chemical vapor deposition. The size of Si QDs was increased with increasing growth temperature and the ratio between silicon-related gas flow and nitrogen-related gas flow. This is because the growth rate of Si QDs decreases due to surface sites blocking by hydrogen. Hydrogen atoms dissociated from $\mathrm{N}-\mathrm{H}$ and $\mathrm{Si}-\mathrm{H}$ could promote the growth of crystalline phase silicon QDs.
\end{abstract}

Keywords

Silicon nitride, Quantum dot, PECVD, Growth temperature, Crystal

\section{Introduction}

Since 1990 [1], silicon quantum dots (Si QDs) have been intensively studied because of the possibility of applications such as compatible metal-oxide-semiconductor (CMOS) devices [2], light source [3-5], fluorescent tags for biomedical applications [6], and their novel applications with electrical and optical functions. For accomplishment of various applications, we need to be trying to understand how to control the size of Si QD embedded in an insulating layer. According to the structural size of $\mathrm{Si} Q D$, this is because confined and/or recombined carriers in Si QD represent their different electrical and optical properties [7-10]. However, few papers were reported about the structural properties of Si QDs embedded in silicon nitride. It is necessary that we understand silicon nanostructures to freely control those structures. In this letter, we report on the structural properties of crystalline Si QDs embedded in silicon nitride grown at low temperature.

\section{Experimental}

Silicon nitride films containing Si QDs were grown by plasma enhanced chemical vapor deposition (PECVD), in which nitrogen-diluted $5 \% \mathrm{SiH}_{4}$ and $\mathrm{NH}_{3}$ were used as the sources of reactants. $\mathrm{A}$ low-doped $p$-type Si wafer (100) with a hole concentration of about $10^{15} \mathrm{~cm}^{-3}$ was employed as a substrate. Growth temperatures were performed at $100{ }^{\circ} \mathrm{C}$ and $300{ }^{\circ} \mathrm{C}$, respectively. For size control of $\mathrm{Si} \mathrm{QD}, \mathrm{NH}_{3}$ flow rates were changed 10 and 30 $\mathrm{sccm}$ fixed $\mathrm{SiH}_{4}$ flow rate of $100 \mathrm{sccm}$ at $300{ }^{\circ} \mathrm{C}$. The plasma power and chamber pressure were fixed at

*Corresponding author: Baek Hyun Kim, Department of Electrical and Computer Engineering, University of Missouri, Columbia, MO 65211, USA

Accepted: June 03, 2019; Published: June 05, 2019

Copyright: (c) $2019 \mathrm{Kim} \mathrm{BH}$. This is an open-access article distributed under the terms of the Creative Commons Attribution License, which permits unrestricted use, distribution, and reproduction in any medium, provided the original author and source are credited.

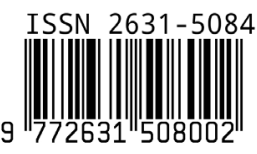

Kim and Seong-Ju. Int J Nanoparticles Nanotech 2019, 5:026 

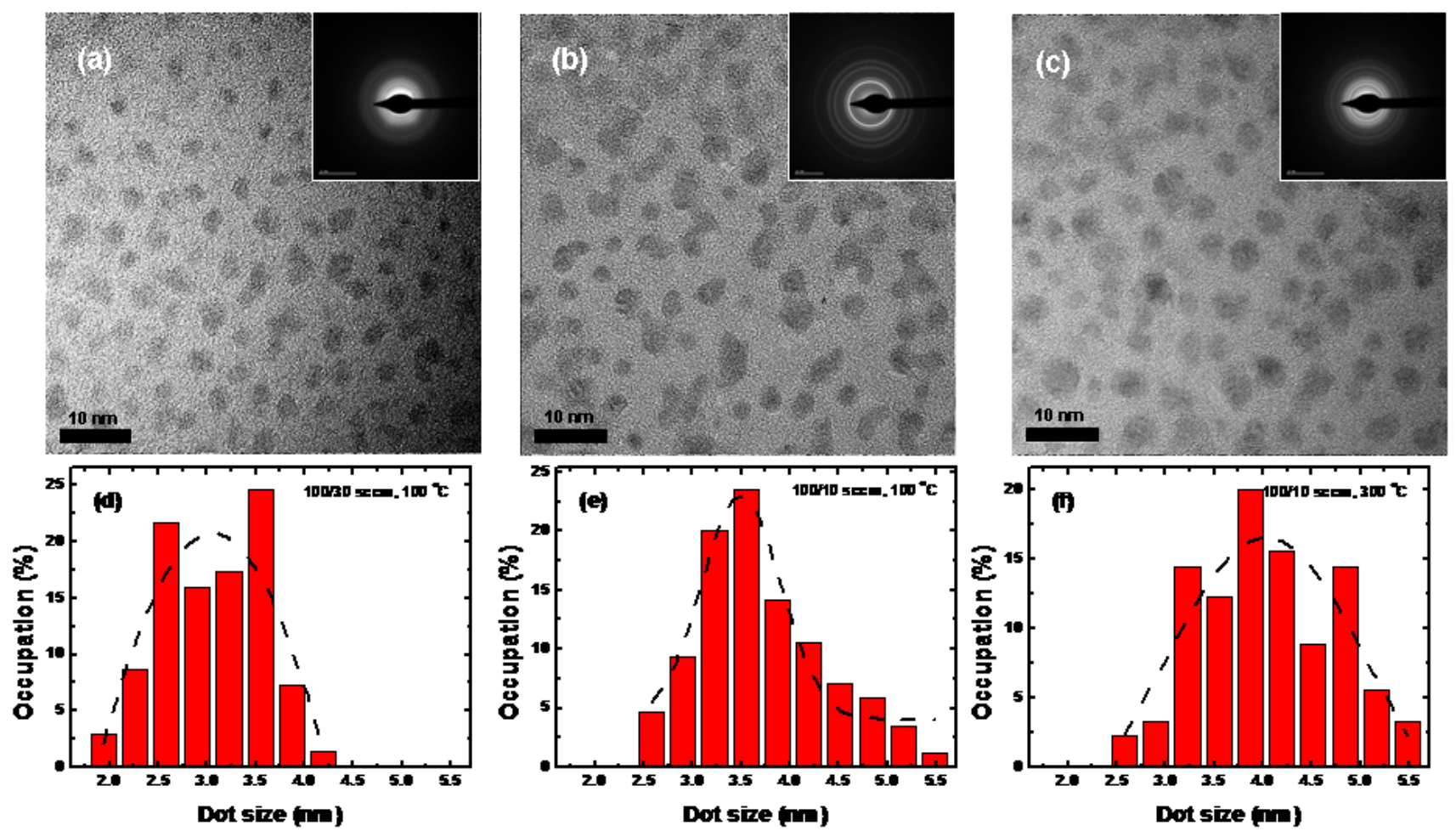

Figure 1: TEM images and TED pattern images (inset) of samples \#1 (a), \#2 (b), and \#3 (c) and the size distribution of samples \#1 (d), \#2 (e), and \#3 (f), as extracted from this TEM images, for Si QDs. The solid curve is Gaussian curve to fit the size distribution of Si QDs.

$10 \mathrm{~W}$ and 1 torr. Growth time of all samples was 10 min. A spectral analyzer system was used for the $\mathrm{PL}$ measurements at room temperature and a HeCd $325 \mathrm{~nm}$ laser was used as an excitation source. Chemical bonds in the film were examined by a Fourier-transform infrared spectroscopy (FTIR) in the wave number range from 400 to $4000 \mathrm{~cm}^{-1}$ with a resolution of $4 \mathrm{~cm}^{-1}$. The structures of Si QD were investigated by a high-resolution transmission electron microscopy (TEM).

\section{Results and Discussions}

To investigate the effect of size distribution of $\mathrm{Si}$ QDs, we performed TEM and transmission electron diffraction (TED) analyses of Si QDs embedded in the silicon nitride film in Figure $1 a$, Figure $1 b$ and Figure $1 \mathrm{c}$ and the size distribution of Si QDs was obtained from the TEM image in Figure 1d, Figure $1 \mathrm{e}$ and Figure 1f. The growth condition of $\# 1$ was the $\mathrm{NH}_{3} / \mathrm{SiH}_{4}$ flow rate of $30 \mathrm{sccm} / 100$ $\mathrm{sccm}$ and the growth temperature of $100{ }^{\circ} \mathrm{C}$, while those of \#2 and \#3 are the $\mathrm{NH}_{3} / \mathrm{SiH}_{4}$ flow rate of $30 \mathrm{sccm} / 100 \mathrm{sccm}$ and the growth temperature of $100{ }^{\circ} \mathrm{C}$ and $300{ }^{\circ} \mathrm{C}$, respectively. The average sizes of \#1, \#2, and \#3 were about 3.06, 3.50, and $4.05 \mathrm{~nm}$ and the density was similar to about $3 \times$ $10^{12} / \mathrm{cm}^{2}$. Most of Si QD samples were essentially

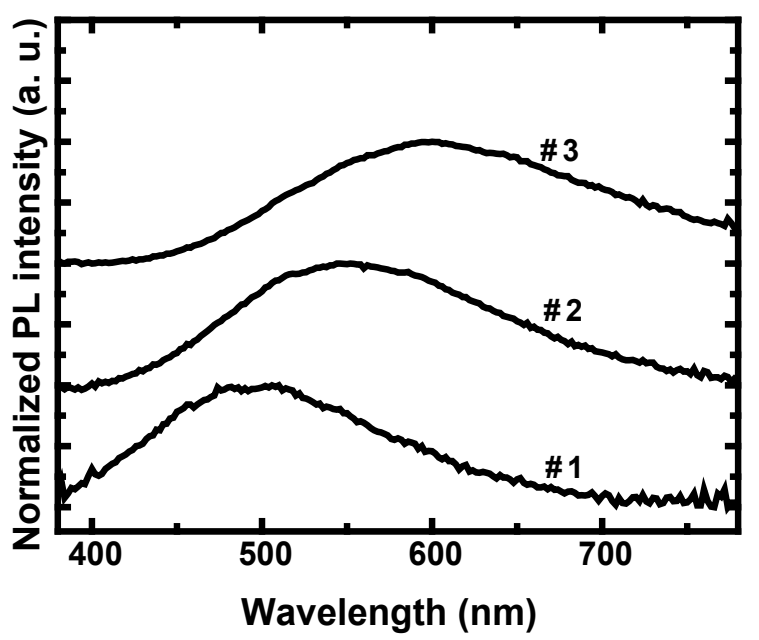

Figure 2: Normalized PL spectra of samples \#1, \#2, and \#3.

in a crystalline state, as revealed by the electron diffraction patterns showing ring patterns as shown in Figure 1. In previous study [11], we reported that the crystallization of $\mathrm{Si}$ QDs is enhanced by the hydrogen dissociated from the $\mathrm{NH}_{3}$ gas. These results reveal that the growth temperature can control the size of Si QDs, while Si QDs are the crystalline phase even at the low temperature. 
PL spectra were red-shifted from 506.36 to $564.56 \mathrm{~nm}$ with decreasing the flow rate of $\mathrm{NH}_{3} /$ $\mathrm{SiH}_{4}$ at $100{ }^{\circ} \mathrm{C}$ as shown in $\# 1$ and $\# 2$ of Figure 2 . Increasing the growth temperature has also made PL spectra red-shifted from 564.56 to $615.75 \mathrm{~nm}$ in the fixed flow rate of gas sources as shown in $\# 2$ and \#3 of Figure 2. Furthermore, PL spectra of Si QDs are red-shifted with increasing growth temperature with fixed flow rate of $\mathrm{NH}_{3} / \mathrm{SiH}_{4}$ (Figure 2b). The shifted PL of Si QDs is in good agreement with TEM analyses grown at various temperatures shown in Figure 1. It is that the shifts of peak positions were reflected as the changed size of Si QD.

The bonding configuration of the film varied with the annealing temperature (Figure 3a). The intense absorption band at $840-870 \mathrm{~cm}^{-1}$ was assigned to the Si-N stretching mode. The band at $3350 \mathrm{~cm}^{-1}$ corresponds to the $\mathrm{N}-\mathrm{H}$ stretching mode. The band at $2180-2200 \mathrm{~cm}^{-1}$ is the result of the Si-H stretching mode. The relative intensities of the three peaks varied with the changed flow rate of $\mathrm{SiH}_{4} /$ $\mathrm{NH}_{3}$ at fixed growth temperature of $100{ }^{\circ} \mathrm{C}$ and the growth temperature of 100 and $300{ }^{\circ} \mathrm{C}$. Figure $3 \mathrm{~b}$ and Figure $3 c$ is a plot of that peak intensities normalized with respect to the as-grown film at $100{ }^{\circ} \mathrm{C}$ with $\mathrm{SH}_{4}$ flow rate of $100 \mathrm{sccm}$ and $\mathrm{NH}_{3}$ flow rate of $10 \mathrm{sccm}$, respectively. When the $\mathrm{NH}_{3}$ flow rate was increased, the $\mathrm{N}-\mathrm{H}$ and $\mathrm{Si}-\mathrm{H}$ peaks diminished in intensity as the increased temperature promoted the release of hydrogen atoms from $\mathrm{N}-\mathrm{H}$ and $\mathrm{Si}-\mathrm{H}$ bonds. When the annealing temperature was increased, the $\mathrm{N}-\mathrm{H}$ and $\mathrm{Si}-\mathrm{H}$ peaks diminished in intensity as the increased temperature promoted the release of hydrogen atoms from $\mathrm{N}-\mathrm{H}$ and $\mathrm{Si}-\mathrm{H}$ bonds. The Si-N peak intensities decreased slight-
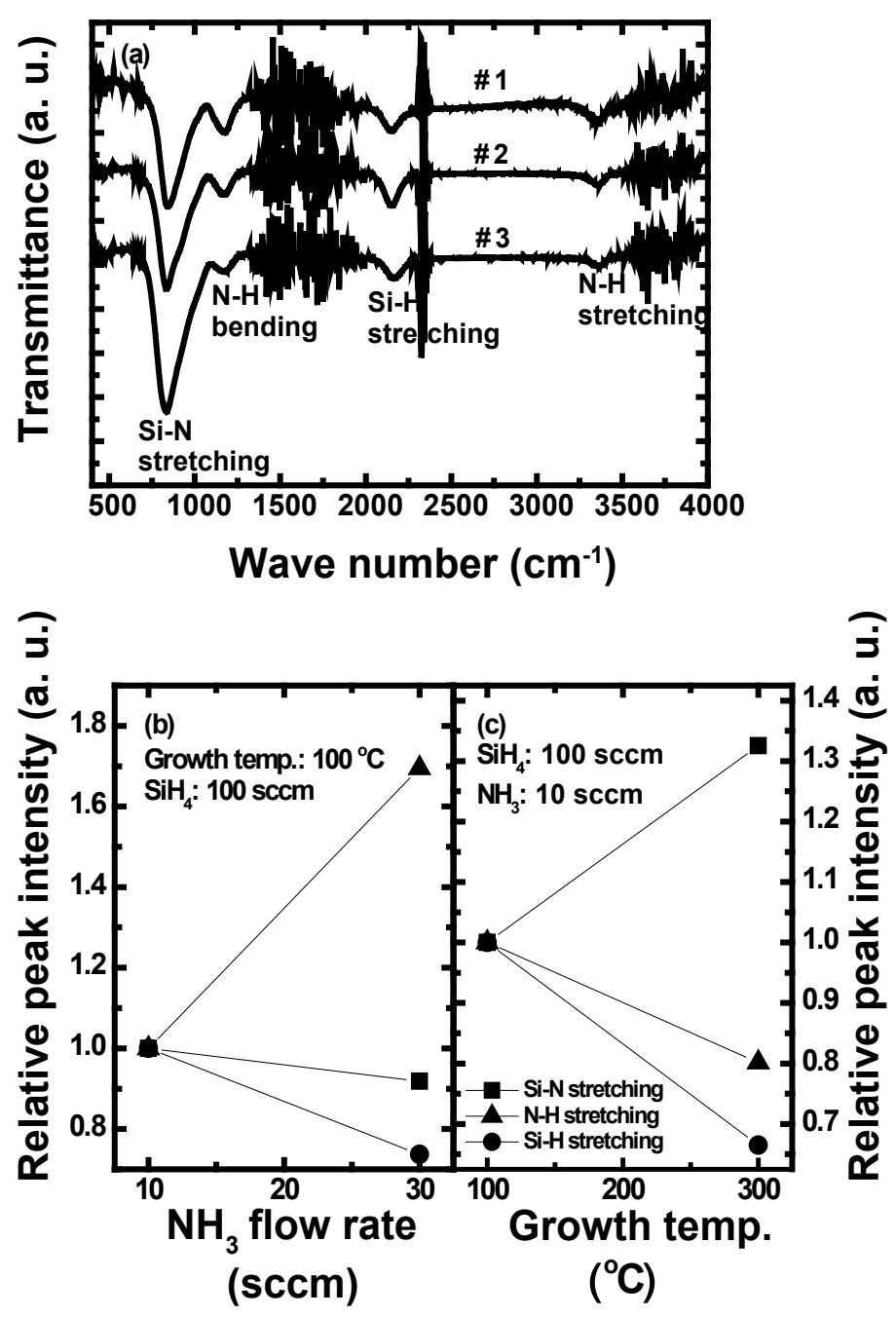

Figure 3: a) FTIR spectra of samples \#1, \#2, and \#3; b) Relative FTIR absorption peak intensities as a function of $\mathrm{NH}_{3}$ flow rate. All samples were grown at the temperature of $100{ }^{\circ} \mathrm{C}$ and $\mathrm{SiH}_{4}$ flow rate of $100 \mathrm{sccm}$; c) Relative FTIR absorption peak intensities as a function of the growth temperature. All samples were grown at $\mathrm{SiH}_{4}$ flow rate of $100 \mathrm{sccm}$ and $\mathrm{NH}_{3}$ flow rate of $10 \mathrm{sccm}$. 
ly with increasing annealing temperature and the peak location was shifted from 841 to $835 \mathrm{~cm}^{-1}$. The reduced Si-N peak intensity suggests that the $\mathrm{Si}$ and $\mathrm{N}$ atoms released from $\mathrm{Si}-\mathrm{H}$ and $\mathrm{N}-\mathrm{H}$ bonds do not rearrange to form $\mathrm{Si}-\mathrm{N}$ bonds. The changes in the $\mathrm{Si}-\mathrm{N}$ peak most likely result from decomposition of the silicon nitride matrix [12].

In order to obtain the effect of growth temperature of Si QDs, we performed the annealing of $\mathrm{Si}$ QDs grown at $100{ }^{\circ} \mathrm{C}$ in PECVD chamber. Figure $4 a$ depicts the variation in PL spectra and peak positions for Si QDs embedded in silicon nitride films as the growth temperature was varied between 100 and $400{ }^{\circ} \mathrm{C}$ in PECVD chamber (Figure 4b). As the growth temperature was increased, the $\mathrm{PL}$ peaks were shifted to lower energy values. These clearly show that the shifts of peak positions were reflected as the temperature increase. Figure $4 \mathrm{c}$ and Figure $4 \mathrm{~d}$ shows PL spectra of annealed samples \#1 and \#2 in the temperature from 100 to 400 ${ }^{\circ} \mathrm{C}$ during $10 \mathrm{~min}$. In order to maintain the same growth circumstance, we used PECVD chamber as an annealing furnace. PL peak positions of annealed sample \#1 were not changed from 564.56 to $566.6 \mathrm{~nm}$, while those of annealed sample \#2 were effectively changed from 506.36 to 547.38 $\mathrm{nm}$. This is because the annealing effect on smaller Si QDs was more effective than that on larger $\mathrm{Si}$ QDs due to their surface area-to-volume ratio. In the range of temperature 100 to $400 \mathrm{C}$, hydrogen atoms between Si QDs and dielectric matrix may be out-diffused and then the formation of new Si-Si
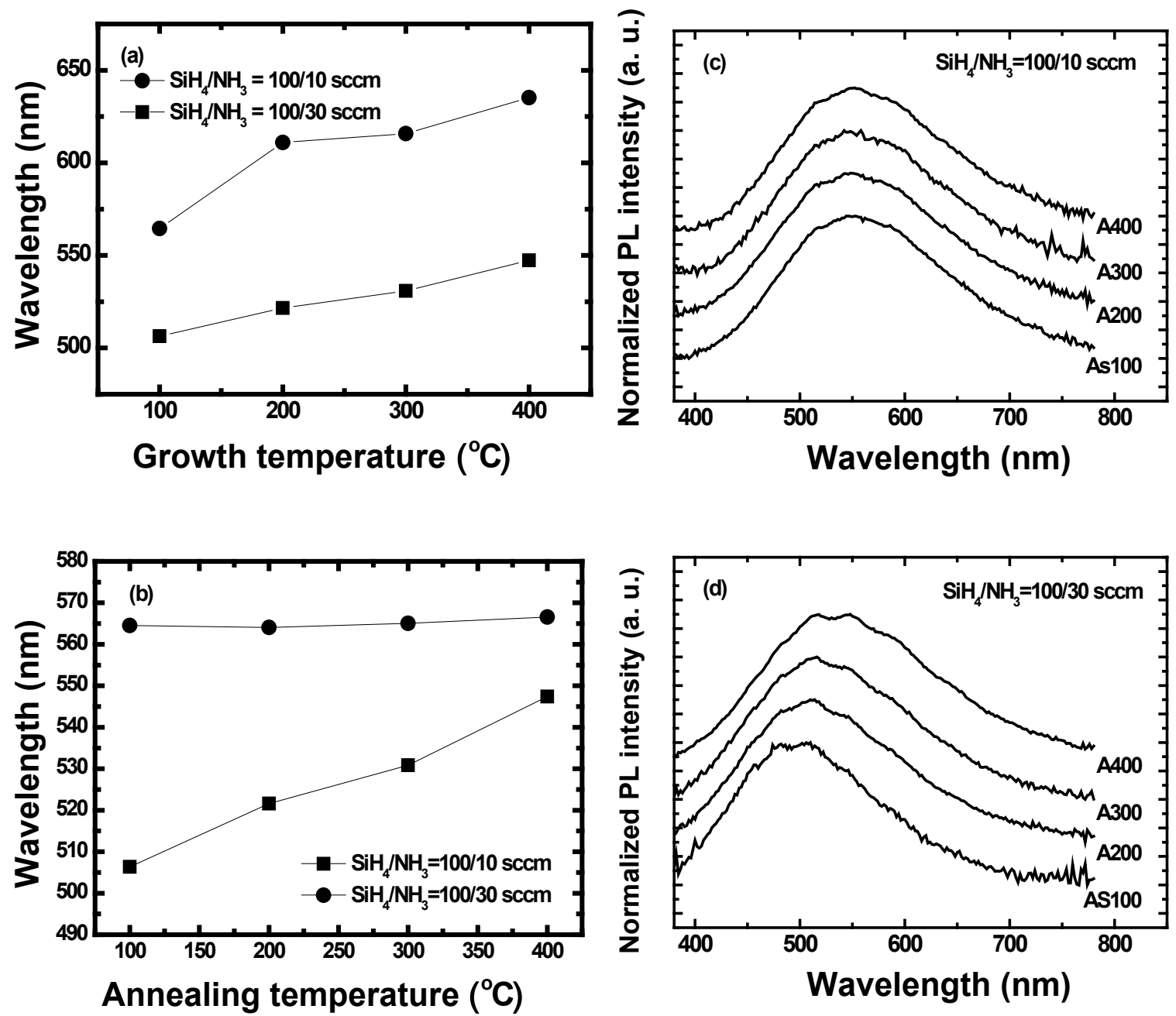

Figure 4: Normalized PL intensities of a) Si QDs as a function of the growth temperature from 100 to $400{ }^{\circ} \mathrm{C}$ and b) Annealed Si QDs temperature from 200 to $400{ }^{\circ} \mathrm{C}$ in PECVD chamber. PL spectra of Si QDs grown using SiH ${ }_{4} /$ $\mathrm{NH}_{3}$ flow rate of $100 / 10 \mathrm{sccm} ; \mathrm{c}$ ) and $100 / 30 \mathrm{sccm}$ as a function of annealing temperatures from 200 to $400{ }^{\circ} \mathrm{C}$ in PECVD chamber. AS100 is the as-deposited sample grown at $100{ }^{\circ} \mathrm{C}$ (AS100). A200, $\mathrm{A} 300$, and $\mathrm{A} 400$ are the samples annealed at $200,300,400{ }^{\circ} \mathrm{C}$, respectively. 
atoms between silicon atoms previously bonded to hydrogen by an interchange bond reaction favored by the tendency for chemical order whereby $\mathrm{Si}-\mathrm{H}$ and $\mathrm{Si}-\mathrm{N}$ bonds are favored at the expense of $\mathrm{N}-\mathrm{H}$ and Si-Si bonds [13-16].

The size of Si QD decrease as temperature is lowered. This is because the growth rate of Si QD decreases due to surface site blocking by hydrogen. The growth rate of Si QDs suppressed more significantly than nucleation as temperature drops, thus one obtains the densest and smallest Si QDs at the lowest possible temperature. The selectivity, or relative ability of a precursor to stick to a surface of Si QDs versus a dielectric surface, largely determines density and size of Si QDs. Atomic silicon is nonselective, i.e. it sticks with unit probability to either surface, thus smooth films or very fine polycrystalline films can result [17]. Hydride gases such as silane prefer to adsorb on the Si QD surfaces as opposed to dielectrics, thus sparse nuclei form on the substrate and grow quickly, eventually producing a coarse poly crystalline film.

\section{Conclusion}

In this study, the effect on growth temperature of crystalline Si QDs grown using PECVD was investigated. The PL peak positions of Si QDs were red-shifted with increasing the growth temperature. This is attributed to the increase in the size of Si QDs because the Si QDs grown at higher temperature rapidly grew compared to the Si QDs grown at lower temperature due to surface site blocking by hydrogen. The presence of hydrogen atoms during the growth of Si QDs could promote the growth of crystalline phase Si QDs at the even low growth temperature.

\section{References}

1. LT Canham (1990) Silicon quantum wire array fabrication by electrochemical and chemical dissolution of wafers. Appl Phys Lett 57: 1046.

2. J Yu, K Chen, Z Ma, X Zhang, X Jiang, et al. (2016) Superior endurance performance of nonvolatile memory devices based on discrete storage in surfacenitrided Si nanocrystals. J Appl Phys 119: 044507.

3. NM Park, TS Kim, SJ Park (2001) Band gap engineering of amorphous silicon quantum dots for light-emitting diodes. Appl Phys Lett 78: 2575.

4. BH Kim, CH Cho, NM Park, GY Sung, SJ Park (2006) $\mathrm{Ni}$ Au contact to silicon quantum dot light-emitting diodes for the enhancement of carrier injection and light extraction efficiency. Appl Phys Lett 89: 063509.

5. BH Kim, CH Cho, JS Mun, MK Kwon, TY Park, et al. (2008) Enhancement of the external quantum efficiency of a silicon quantum dot light-emitting diode by localized surface plasmons. Adv Mater 20: 3100-3104.

6. J Fan, PK Chu (2010) Group IV nanoparticles: synthesis, properties, and biological applications. Small 6: 2080-2098.

7. S Furukawa, T Miyasato (1988) Quantum size effects on the optical band gap of microcrystalline $\mathrm{Si}: \mathrm{H}$. Phys Rev B: Condens Matter 38: 5726.

8. NM Park, CJ Choi, TY Seong, SJ Park (2001) Quantum Confinement in Amorphous Silicon Quantum Dots Embedded in Silicon Nitride. Phys Rev Lett 86: 1355.

9. TW Kim, BH Kim, CH Cho, SJ Park (2006) Quantum confinement effect in crystalline silicon quantum dots in silicon nitride grown using $\mathrm{SiH}_{4}$ and $\mathrm{NH}_{3}$. Appl Phys Lett 88: 123102.

10.AMP Botas, RAS Ferreira, RN Pereira, RJ Anthony, T Moura, et al. (2014) High Quantum Yield Dual Emission from Gas-Phase Grown Crystalline Si Nanoparticles. J Phys Chem C 118: 10375-10383.

11.BH Kim, CH Cho, TW Kim, NM Park, GY Sung, et al. (2005) Photoluminescence of silicon quantum dots in silicon nitride grown by $\mathrm{NH}_{3}$ and $\mathrm{SiH}_{4}$. Appl Phys Lett 86: 091908.

12.GN Parsons, JH Souk, J Batey (1991) Low hydrogen content stoichiometric silicon nitride films deposited by plasma-enhanced chemical vapor deposition. J Appl Phys 70: 1553.

13.CH Lin, SC Lee, YF Chen (1993) Strong roomtemperature photoluminescence of hydrogenated amorphous silicon oxide and its correlation to porous silicon. Appl Phys Lett 63: 902.

14.A Aydinli, A Serpengüzel, D Vardar (1996) Visible photoluminescence from low temperature deposited hydrogenated amorphous silicon nitride. Solid State Commun 98: 273-277.

15.FL Martínez, A del Prado, I Mártil, G González-Diaz, W Bohne, et al. (2001) Molecular models and activation energies for bonding rearrangement in plasmadeposited $\mathrm{a}-\mathrm{SiN}_{\mathrm{x}}: \mathrm{H}$ dielectric thin films treated by rapid thermal annealing. Phys Rev B 63: 245320.

16. BH Kim, RF Davis, SJ Park (2010) Optical property of silicon quantum dots embedded in silicon nitride by thermal annealing. Thin Solid Films 518: 1744-1746.

17.WT Leach, J Zhu, JG Ekerdt (2002) Cracking assisted nucleation in chemical vapor deposition of silicon nanoparticles on silicon dioxide. J Crystal Growth 240: 415-422. 